\title{
Characteristics of large thermal energy storage systems in Poland
}

\author{
Ryszard Zwierzchowski ${ }^{1, *}$ \\ ${ }^{1}$ Department of Heating and Gas Engineering, Faculty of Building Services, Hydro and \\ Environmental Engineering, Warsaw University of Technology, ul. Nowowiejska 20, \\ 00-653 Warsaw, Poland
}

\begin{abstract}
In District Heating Systems (DHS) there are significant fluctuations in demand for heat by consumers during both the heating and the summer seasons. These variations are considered primarily in the 24-hour time horizon. These problems are aggravated further if the DHS is supplied by a CHP plant, because fluctuations in heat demand adversely affect to a significant degree the stable production of electricity at high overall efficiency. Therefore, introducing Thermal Energy Storage (TES) would be highly recommended on these grounds alone. The characteristics of Large (i.e. over $10000 \mathrm{~m}^{3}$ ) TES in operation in Poland are presented. Information is given regarding new projects (currently in design or construction) that apply TES technology in DHS in Poland. The paper looks at the methodology used in Poland to select the TES system for a particular DHS, i.e., procedure for calculating capacity of the TES tank and the system to prevent water stored in the tank from absorbing oxygen from atmospheric air. Implementation of TES in DHS is treated as a recommended technology in the Polish District Heating sector. This technology offers great opportunities to improve the operating conditions of DHS, cutting energy production costs and emissions of pollutants to the atmosphere.
\end{abstract}

\section{Introduction}

In District Heating Systems (DHS) there are significant fluctuations in consumer demand for heat during both the heating and the summer seasons. These variations are considered primarily in the 24-hour time horizon. During the heating season the fluctuations are associated with rapid changes in meteorological conditions, such as outside air temperature, solar radiation and wind speed. During the summer season the fluctuations are associated mainly with variable demand for domestic hot water. These variations in the consumer demand for heat cause significant problems in operational terms, forcing frequent changes to boilers' heat power in heat sources at both Heat Only Boilers (HOB) and Combined Heat and Power (CHP) plants, which in turn lead to a reduction in the efficiency of heat and power generation and in the security of heat delivery to consumers.

\footnotetext{
* Corresponding author: ryszard.zwierzchowski@is.pw.edu.pl
} 
These problems are aggravated further if the DHS is supplied by a CHP plant, because fluctuations in heat demand adversely affect to a significant degree the stable production of electricity at high overall efficiency. Introducing additional thermal capacity to the DHS in the form of Thermal Energy Storage (TES) would be highly recommended on these grounds alone. The EU shares this approach, as the Energy Efficiency Directive (2012/27/EU) supports the broad application of TES in DHS.

Use of TES is essential both in the process of upgrading existing CHP or HOB plants as well as in the construction of new plants. When planning the construction of new plants, the use of TES can significantly reduce their size (heating capacity) and structure, i.e., decrease the number of or eliminate peak boilers. These activities will contribute to a reduction in the investment costs required for heat generating units. However, the greatest economic and environmental effects relate to the current operation of energy sources supplying DHS, and with properly selected and designed TES systems.

\section{Accumulation of heat in water, thermally stratified TES}

Heat storage in water, thermally stratified TES is one of the easiest ways to collect thermal energy [1-4]. The TES is a tank that stores thermal energy in the form of hot water. From a thermodynamic point of view, water is one of the best substances to store energy in the form of sensible heat. The heat capacity of water (specific heat) is approximately four times higher than air and most inorganic materials, as well as from four to ten times higher than most metals.

\subsection{The principle of operation of thermally stratified TES}

In TES hot water collects in the top part of the tank and is separated by a relatively narrow thermocline from cold water at the bottom of the TES tank, Fig. 1. The height of this type of tank can be as much as tens of meters, and their capacity reaches tens of thousands of cubic meters. When charging the TES, hot water from boilers (or heat exchangers) pushes the cold water towards the bottom of the tank, which then flows into the boilers. When discharging the TES, return water from DHS called "cold water", displaces the hot water towards the top of the tank and then to the supply pipeline of the DHS. The water level in the TES tank remains practically unchanged, only the amount of hot and cold water in the tank changes, as does the location of the thermocline. In order to avoid oxygen penetrating from the ambient air to the hot water stored in the TES tank, a steam bed is applied above the water in the tank.

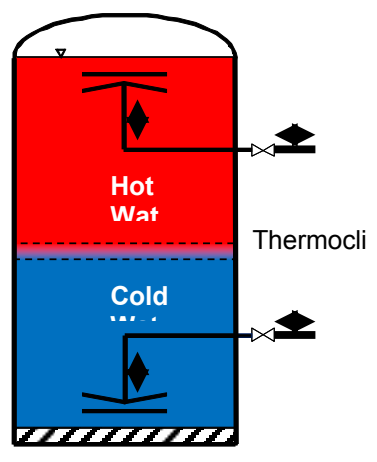

Fig. 1. Principle of Operation of the water, thermally stratified TES. 


\subsection{Breakdown of the water, thermally stratified TES}

The water is divided in thermally stratified TES due to various criteria, as presented in [15]. So, due to operation pressure, TES systems can be divided into:

$>$ Pressurized TES,

$>$ Non-pressurized TES,

- TES included in thermal system directly,

- TES included in thermal system indirectly (through heat exchangers).

In terms of size, TES tanks can be divided into:

$>$ TES - large, with a capacity of more than $10,000 \mathrm{~m}^{3}$,

$>$ TES - medium, with a capacity of 1,000 to $10,000 \mathrm{~m}^{3}$,

$>$ TES - small, with a capacity of less than $1,000 \mathrm{~m}^{3}$.

\subsection{Basic tasks of TES}

The use of TES in DHS increases operational efficiency, production and delivery of heat to the end user, and thus its cost [1-4]. Hence, programs to modernize DHS should take into account the possibility of accumulating heat in the system through the use of TES. The basic task of the TES system is heat source load leveling when heat demand by consumers is variable [5]. Other main roles are listed below:

- to increase production in cogeneration mode in the CHP plant,

- to produce more electricity in the CHP plant during periods of peak demand,

- to cover peak heat demand,

- to increase the operational efficiency of the energy generating units through stable performance with balanced heat input,

- to reduce fuel consumption through stable operation with a balanced load,

- to reduce pollutant emissions through lower fuel consumption and stable operation with a balanced load,

- to keep maintenance costs low through a low failure rate achieved by stable and continuous operation of the generating units,

- to avoid temporary run of peak boilers to meet changing consumer heat demand,

- to reduce pollutant emissions through avoiding running peak boilers,

- to reduce water losses, as TES plays the role of expansion vessel for DHS.

\section{Selection of TES for the District Heating System}

To select the best TES system for a particular DHS, it is necessary to collect and analyze operational data for the heat source (CHP or HOB) and for the entire DHS (temperature, pressure, water flows, weather conditions, etc.). The analysis should cover at least the last 2-3 years, to establish the trends and to confirm the existing forecasts regarding future operation of the DHS

The required capacity of the TES tank for full heat accumulation in a 24-hour scale was estimated. The estimation was performed on the basis of the hourly variation in heat demand by the DHS over the period of analysis [1, 5]. A TES system with full heat accumulation is one that is able to compensate for fluctuations in the heat demand of the DHS, while simultaneously providing the operation of energy generating units with constant, stable power.

On the other hand, the calculated volume of the TES tank with full heat accumulation $\left(V_{T E S(c a l)}\right)$ should take into account the share of the non-useful space of the tank and its efficiency. 
A variant of the TES tank with full accumulation is the basic operational variant. Other variants that should be considered depend on local and national circumstances. For example, for CHP Siekierki beyond the basic variant, the considered variants have taken into account the consequences of participation in the balancing electricity market and sales of electricity with a variable price per day. In turn, for example, in the Nordic countries a variant is often considered that is associated with shutdown of the CHP plant for the weekend. Sometimes, in addition, location-connection variants are considered. They depend on the location of the TES and how it hooked up to the thermal system of the CHP plant. These variants differ mainly in investment and operational costs. The final size of the TES tank verifies the classic economic analysis carried out for each operational and possibly location-connection variants e.g. for three sizes of TES tank [6]:

1) $\quad V_{T E S I}=V_{T E S(c a l)}$,

2) $V_{T E S 2}=0,8 V_{T E S(c a l) \text {, }}$

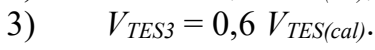

Economic analysis includes investment costs of constructing TES tanks of different sizes, taking into account the economic effects that can be obtained in individual, analyzed variants.

\section{Characteristics of large TES systems operated in Poland}

Large TES systems in DHS are a recent development in Poland. The first large TES system was built in Poland in the CHP Siekierki plant in Warsaw and has been operational since 2009, another four went operational in the period 2011-2015: CHP Cracow, CHP Bialystok, CHP Bielsko Biala [6], CHP Ostroleka, and a sixth is currently in the start-up phase: CHP Torun.

The largest TES in Poland is at CHP Siekierki. It has a water capacity of $30,400 \mathrm{~m}^{3}$ and a thermal capacity of approx. 1,600 MWh. It is currently in its seventh full heating season. The highest TES tank was built for CHP Bielsko Biala, and its total height including the top of the roof is approximately $64.5 \mathrm{~m}$. The big tank height of the TES is due to the significant elevation variation of the District Heating Network (DHN) in the city.

The first TES system with a capacity of approx. $750 \mathrm{~m}^{3}$ (thermal capacity approx. $26 \mathrm{MWh}$ ), has been in operation since 2002 in PEC in Siedlce [5]. below.

The technical characteristics of large TES systems built in Poland are presented in brief

\subsection{TES in Siekierki CHP plant in Warsaw}

Siekierki CHP plant in Warsaw is a second largest CHP plant in Europe and supply with heat the biggest DHS in EU with pipelines length over 1,800 km and over 19,000 facilities (heat consumers). The DHS covers around $80 \%$ of the city heat demand.

Below, short technical characteristic of the TES in Siekierki CHP plant is presented:

1. The design of the TES was completed in 2007 [6]; the TES after a start-up period has been operational since March 2009.

2. Technical parameters of the TES:

- type

- volume

- diameter

- height of the tank cylindrical part

- radius of the roof sphere

full of water, non-pressurized

$30,400 \mathrm{~m}^{3}$

$30.0 \mathrm{~m}$

$43.0 \mathrm{~m}$

$45.0 \mathrm{~m}$ 
- thickness of insulation

- flowrate of charging/ discharging

- temperature of the network water

- protection against oxygen absorption to water

- weight of the tank (without insulation)
$500 \mathrm{~mm}$

$4,500 \mathrm{Mg} / \mathrm{h}$

$98 / 40^{\circ} \mathrm{C}$

steam bed

c. $53,000 \mathrm{~kg}$

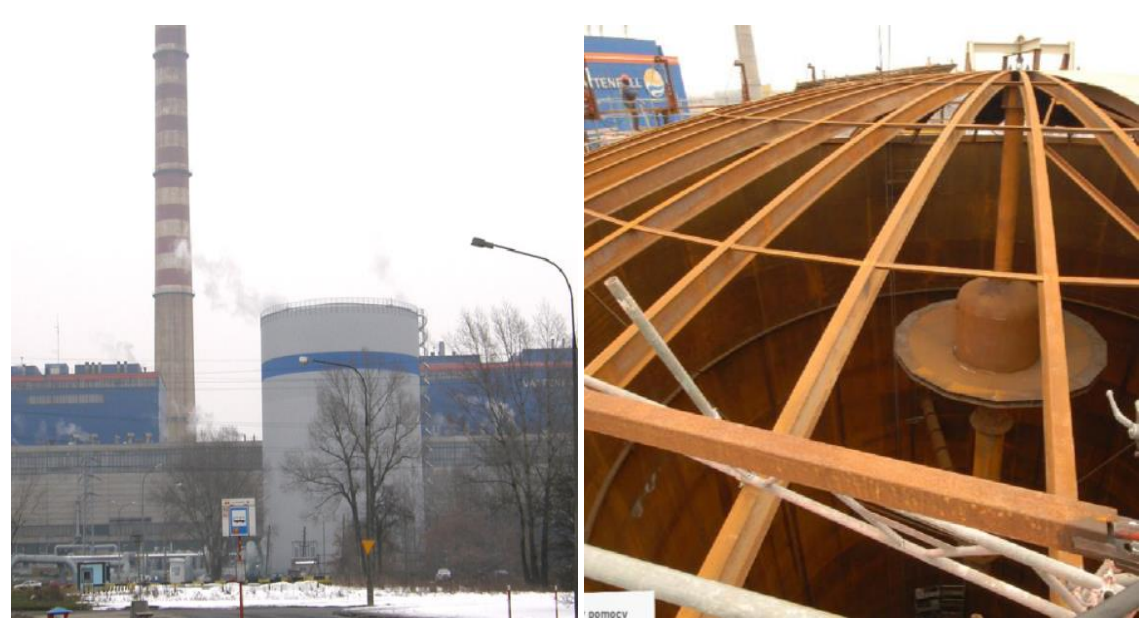

Fig. 2. TES in Siekierki CHP plant.

Fig. 3. Upper orifice in the tank of TES.

Due to application of the TES in Siekierki CHP plant, only in 2009 year i.e. in the first year of the TES operation, overall efficiency of energy generation (heat and electricity) by the plant has increased from $86.6 \%$ to $87.3 \%$ [6]. Also, temporary run of peak water boilers was reduced by nearly $70 \%$, production in cogeneration mode in the CHP plant was increased significantly and reduction of pollutant emissions i.e. dust, $\mathrm{SO}_{2}, \mathrm{NO}_{\mathrm{x}}$ to the atmosphere was observed [6].

From 2009 up to now, the TES system in CHP Siekierki is in continuous operation, both in heating and summer seasons and compensate variable heat demand by consumers in 24-hours mode.

\subsection{TES in Cracow CHP plant}

The CHP plant in Cracow supply with heat the city with population over 700,000 . The DHS consists of pipelines with length over $830 \mathrm{~km}$ and 8,500 heat consumers (facilities).

Below, short technical characteristic of the TES in Cracow CHP plant is presented:

1. The TES was designed in 2009 [6]; has been operational since 2011.

2. Technical parameters of the TES:

- type

- volume

- diameter

- height of the tank cylindrical part

- radius of the roof sphere full of water, non-pressurized

$20,015 \mathrm{~m}^{3}$

$23.0 \mathrm{~m}$

$48.2 \mathrm{~m}$ 
- thickness of insulation $300 \mathrm{~mm}$

- flowrate of charging/ discharging $2,600 \mathrm{Mg} / \mathrm{h}$

- temperature of the network water $98 / 40^{\circ} \mathrm{C}$

- protection against oxygen steam absorption to water bed

- weight of the tank c. $38,000 \mathrm{~kg}$

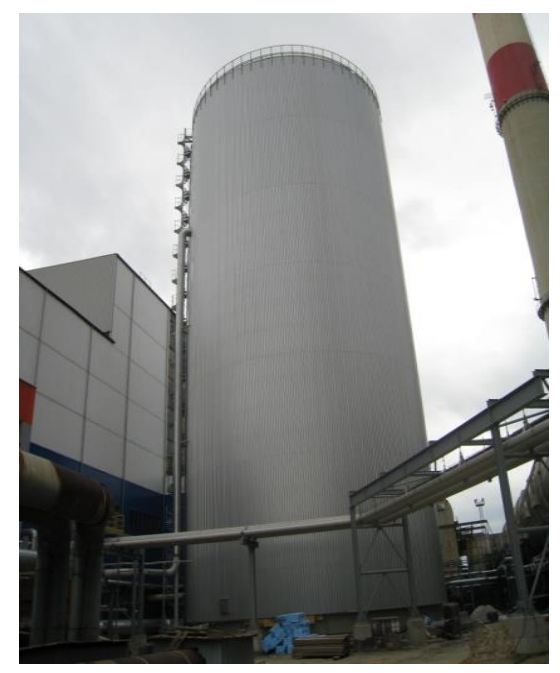

Fig. 6. TES in Cracow CHP plant.

\subsection{TES in Bialystok CHP plant}

The DHS in Bialystok consists of pipelines with length over $270 \mathrm{~km}$ and 2,200 heat distribution substations and supply with heat the city with population app. 300,000.

Below, short technical characteristic of the TES in Bialystok CHP plant is presented:

1. The TES was designed in 2009/10 [6]; has been operational since 2011 .

2. Technical parameters of the TES:

- type

- volume

- diameter

- height of the tank cylindrical part

- radius of the roof sphere

- thickness of insulation

- flowrate of charging/ discharging

- temperature of the network water

- protection against oxygen full of water, non-pressurized $12,800 \mathrm{~m}^{3}$ $21.0 \mathrm{~m}$

$37.0 \mathrm{~m}$

$31.5 \mathrm{~m}$ $500 \mathrm{~mm}$

$1,500 \mathrm{Mg} / \mathrm{h}$

$98 / 40^{\circ} \mathrm{C}$

steam 
absorption to water

- weight of the tank

(without of insulation): bed

c. $30,000 \mathrm{~kg}$

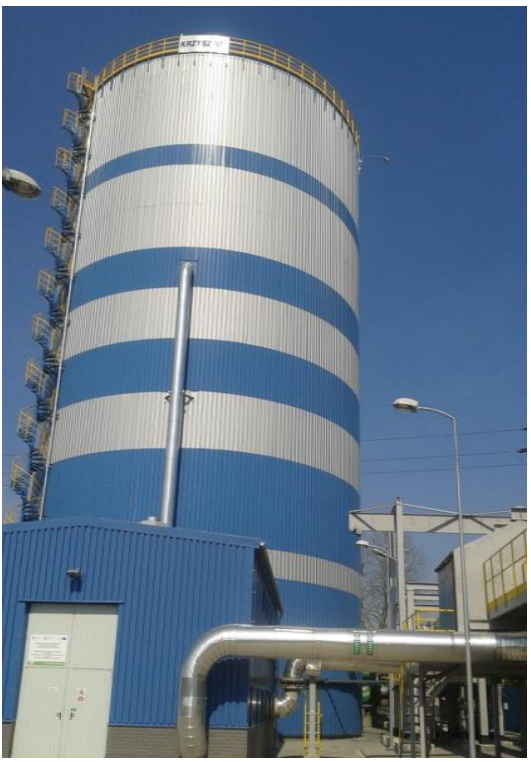

Fig. 7. TES in Bialystok CHP plant.

\subsection{TES in Bielsko Biała CHP plant}

The DHS in Bialystok consists of pipelines with length over $170 \mathrm{~km}$ and 900 heat distribution substations and supply with heat the city with population over 170,000.

1. The design of the TES was completed in 2011/12 [6]; the TES after a start-up period has been operational since autumn 2013.

2. Technical parameters of the TES:

- type

- volume

- diameter

- height of the tank cylindrical part

- radius of the roof sphere

- thickness of insulation

- flowrate of charging/ discharging

- temperature of the network water

- protection against oxygen absorption to water

- weight of the tank (without of insulation) full of water, non-pressurized $21,450 \mathrm{~m}^{3}$ $21.0 \mathrm{~m}$

$62.0 \mathrm{~m}$

$31.5 \mathrm{~m}$

$500 \mathrm{~mm}$

$2,500 \mathrm{Mg} / \mathrm{h}$

$98 / 40^{\circ} \mathrm{C}$

steam

bed

c. $44,000 \mathrm{~kg}$ 


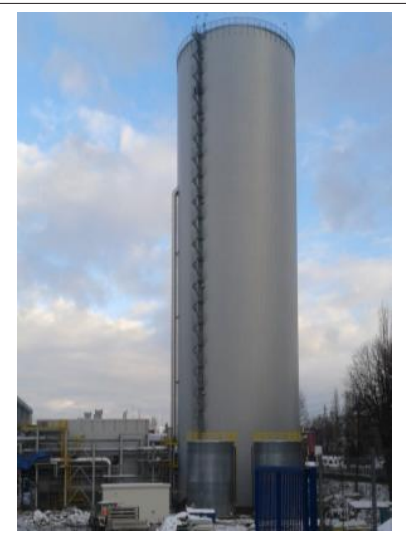

Fig. 8. TES in Bielsko Biała CHP plant.

\subsection{TES in Ostroleka power plant}

1. The design of the TES was completed in 2013; the TES after a start-up period has been operational since 2014 .

2. Technical parameters of the TES:

- type

- volume

- diameter

- height of the tank cylindrical part

- thickness of insulation

- flowrate of charging/ discharging

- temperature of the network water

- protection against oxygen absorption to water

- weight of the tank (without of insulation) c. $35,000 \mathrm{~kg}$ full of water, non-pressurized

c. $13,000 \mathrm{~m}^{3}$

$22.0 \mathrm{~m}$

$37.25 \mathrm{~m}$

$500 \mathrm{~mm}$

c. $1,500 \mathrm{Mg} / \mathrm{h}$

$98 / 40^{\circ} \mathrm{C}$

steam

bed

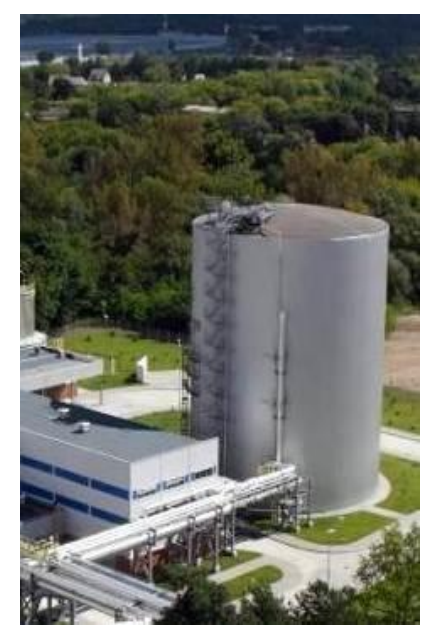

Fig. 9. TES in Ostroleka Power plant. 


\subsection{TES in Torun CHP plant}

1. The design of the TES was completed in 2015/16; it is scheduled to go operational in Fall 2017.

2. Technical parameters of the TES:

- type

- volume

- diameter

- height of the tank cylindrical part

- thickness of insulation

- flowrate of charging/ discharging

- temperature of the network water

- protection against oxygen absorption to water

- weight of the tank (without of insulation) full of water, non-pressurized $13,200 \mathrm{~m}^{3}$ $20.0 \mathrm{~m}$

$42.0 \mathrm{~m}$

$405 \mathrm{~mm}$

c. $1,500 \mathrm{Mg} / \mathrm{h}$

$98 / 45^{\circ} \mathrm{C}$

steam

bed

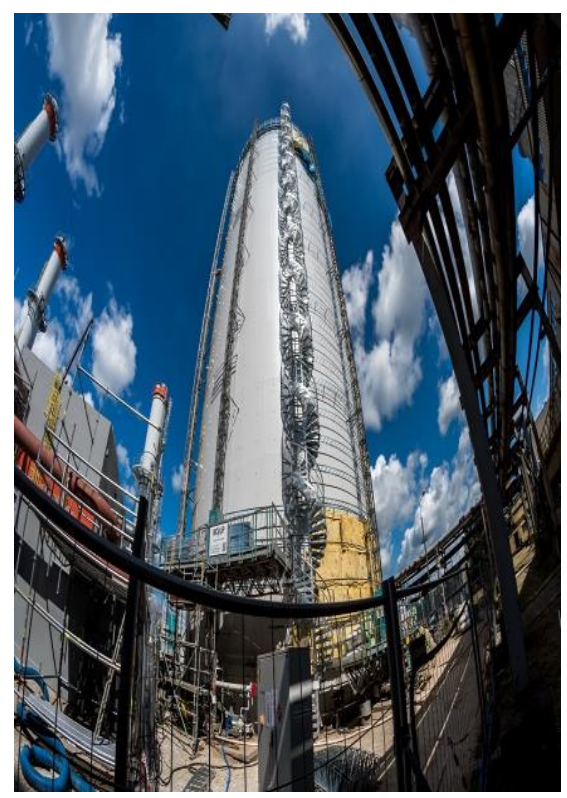

Fig. 10. TES in Torun CHP plant.

\section{Summary and conclusions}

Technologies associated with the use of TES systems are still something of a novelty in the Polish DHS sector. They offer great opportunities to improve the operating conditions of DHS and the economics of the production of heat and electricity, reducing emissions of pollutants into the atmosphere and increasing security of energy supply to consumers. The application of TES in the DHS facilitates the efficient running of energy sources, i.e. it lets 
energy generating units (boilers, turbomachinery) operate at high efficiency and reduces to a minimum the number of start-ups of peak boilers [5].

In the past four years the European Union has adopted two fundamental and harmonized Directives of the EU Parliament and the Council, which create a real basis for achieving the objectives of the EU's energy strategy and protection of the environment by the 2020, i.e.:

1. Directive of the European Parliament and of the Council of 2012/27/EC of 25.10.2012 on Energy Efficiency.

2. Directive of the European Parliament and of the Council 2010/75/EU of 24/11/2010 on Industrial Emissions (integrated pollution prevention and control).

Both Directives are extremely important for the Polish district heating sector, influence its development and modernization, efficiency and competitiveness, and meet environmental concerns. The obligations arising from them will be extremely difficult to fulfil in the Polish heating sector, particularly as regards emissions of gaseous pollutants, which pose a potent threat to the very existence of the sector. Nevertheless, there are relevant support programs in place and widespread information about potential threats [6].

Directive 2012/27/EU, which creates a common policy framework to reduce about $20 \%$ of primary energy consumption in the EU by 2020, cites measures to yield significant improvements in energy efficiency in district heating systems. This Directive has absorbed the existing Directive 2004/8/EC on the promotion of cogeneration based on useful heat demand in the internal energy market. Maximization of energy production in cogeneration will require the use of TES systems to improve the overall efficiency of energy production.

Current status of large TES systems i.e. with capacity over $10,000 \mathrm{~m}^{3}$ :

$>5$ TES systems are in operation,

> 1 TES system is under commissioning and will go operational in Fall 2017,

$>2$ TES systems are at the design stage,

$>2$ TES systems are at the pre-design stage.

In addition to large TES systems, there are also a few medium (e.g. CHP Mielec) and small (e.g. CHP Siedlce) TES systems operating in Poland.

\section{References}

1. J.A. Dahl, L.R. Hermansson, Proceedings of the $6^{\text {th }}$ International Conference on Thermal Energy Storage - Calorstock'9., Espoo, Finland, 403-410 (1994)

2. I. Dincer, M.A. Rosen, Thermal Energy Storage. Systems and Applications, Second Edition (John Wiley \& Sons, Ltd., Chichester, England, 2011)

3. F. Dinter, M. Ger, R. Tamme, Thermal Energy Storage for Commercial Applications (Springer-Verlag, Berlin, 1994)

4. S. Gnuchtel, T. Sander, $7^{\text {Th }}$ International Symposium on District Heating and Cooling. Lund, Sweden (1999)

5. R. Zwierzchowski, The International Conference on Energy Efficiency and Control of Air Pollutants from Utilization of Fossil Fuels (Wroclaw, Poland, 181, 2009)

6. R. Zwierzchowski, Politechnika Warszawska, Prace Naukowe. Inzynieria Srodowiska 64, 1-136 (2013) 